\title{
CIDADANIA E DIREITOS HUMANOS
}

\author{
ÁLVARO LAZZARINI*
}

1. Considerações iniciais. 2. Cidadania. 3. Direitos Humanos Fundamentais. 3.1 Proteção às vítimas. Considerações. 4. O Poder Judiciário como instrumento de defesa da Cidadania e dos Direitos Humanos Fundamentais. 5. Conclusão.

\section{Considerações iniciais}

Na Encíclica “Divini Redemptoris" - escrevi anteriormente ${ }^{1}-$, Pio XI assentou que "A sociedade fez-se para o homem e não o homem para a sociedade". Em outras palavras, como observou Monsenhor Guerry ${ }^{2}$, Arcebispo de Cambrai, "segundo a doutrina social da igreja, a sociedade está ao serviço da pessoa humana para respeitar a sua dignidade, permitir-lhe atingir o seu fim e conseguir o seu completo desenvolvimento humano", salientando, em seguida, que a máxima de Pio $\mathrm{XI}$ é audaciosa, mas ela "não quer dizer que a sociedade se encontre subordinada à utilidade egoística do indivíduo, quer antes dizer, porém que o homem é um ser social por natureza e só em sociedade pode aperfeiçoar as suas faculdades, graças à proteção que esta diligência para a sua vida física, intelectual, moral, familiar e social. Por outras palavras - continuou Monsenhor Guerry -, o homem é uma pessoa humana que realizará a sua plena autonomia na sua união com os outros e na sua colaboração com os restantes membros da sociedade". O homem tem a sua dignidade, porque, antes de tudo foi criado à imagem e semelhança de Deus, como salientado na Bíblia, na passagem da Criação (Gênesis, I, 27). Daí por que Pio XI

* Desembargador, $1^{\circ}$ Vice-Presidente do Tribunal de Justiça do Estado de São Paulo, Professor de Direito Administrativo, Sócio Colaborador do Instituto dos Advogados de São Paulo, Membro do Instituto Pimenta Bueno e da Associação dos Constitucionalistas da Universidade de São Paulo. 1 LAZZARINI, Alvaro. Estudos de Direito Administrativo, 2* ed., 1999, Editora Revista dos Tribunais, São Paulo, p. 181-182.

2 GUERRY, Monsenhor. A Doutrina Social da Igreja, Livraria Sampedro Ed., Lisboa, Portugal, p. 55-56.

R. Dir. Adm.,

Rio de Janeiro, 223: 105-114, jan./mar. 2001 
disse ser o homem responsável pelos seus atos e destino, capaz de governar-se por si mesmo, encontrando aí a sua mais alta dignidade ${ }^{3}$. Porém - como registrei -, ao que se verifica e o aponta Monsenhor Guerry, "o homem moderno pretende abster-se de Deus. Repudia o princípio divino da sua dignidade. Para ele o valor supremo já não é Deus, mas o homem. O resultado é o 'drama do humanismo ateu', cuja história foi escrita em trechos expressivos. 'Estamos atualmente preocupados em verificar experimentalmente, que, onde não existe Deus, não existe homem também (...) De fato - insistiu Monsenhor Guerry ${ }^{4}$ —, Já não há homem porque já não há nada que seja superior ao homem". Mas — e assim ponderei —. "é o homem em sociedade que devemos tratar. Pio XII já dissera que. para os homens, é "exigência legítima o serem considerados e tratados, não como objetos mas como sujeitos na vida social. especialmente no Estado e na economia nacional", 5 .

\section{Cidadania}

Adverte Milena Petters Melo ${ }^{6}$ que "A cidadania tem sido um dos temas mais frequientes da retórica política e do discurso das ciências sociais no Brasil. A ampliação do debate, no entanto, não trouxe univocidade ao termo. Contrariamente, quanto mais se fala em cidadania, tanto maior torna-se a ambigüidade da expressão. Já advertia Hegel, 'a maneira mais comum de iludir-se a si mesmo e de iludir os outros consiste em supor no conhecer algo já conhecido e deixá-lo como tal'. A reflexão com vistas a uma nova praxis pressupõe a elucidação dos conceitos abarcados pelo conceito de cidadania, por isso, para que não se torne este conceito como de todo conhecido e a sua discussão como pronta e pacífica, é que se passa ao seu enfrentamento".

Temos, assim, de lembrar que o homem em sociedade deve ser considerado um cidadão, ou seja, na lição de Juan Blasco Quintana", aquele que "é o natural ou morador de uma cidade, o habitante das cidades antigas ou Estados modernos, que é sujeito de direitos políticos e que ao exercê-los intervém no governo do país. $\mathrm{O}$ fato de ser cidadão propicia a cidadania, que é a condição jurídica que podem ostentar as pessoas físicas e morais, e que por expressar o vínculo entre o Estado e seus membros implica de um lado, submissão à autoridade, e de outro, o exercício de direito. O cidadão é membro ativo de uma sociedade política independente. A cidadania se diferencia da nacionalidade porque esta supõe a mera qualidade de

3. PIO XII. apud Monsenhor Guerry, ob. cit., p. 57.

4 GUERRY, Monsenhor. Obra cit., p. 59.

5 PIO XII, apud Monsenhor Guerry, Obra cit., 76.

6 MELO. Milena Petters, et alii. Cidadania: Subsídios Teóricos para uma Nova Praxis, "Direitos Humanos como Educação para a Justiça", Organizador: Reinaldo Pereira e Silva. Editora Ltr., São Paulo, 1998. p. 77 e seguintes.

7 QUINTANA, Juan Blasco. Dicionário de Ciências Sociais, Coordenação Geral de Benedicto Silva, Editora da Fundação Getúlio Vargas, Rio de Janeiro. 1986, verbete "Cidadão", p. 177. 
pertencer a uma nação, enquanto que o conceito da cidadania pressupõe a condição de ser membro ativo do Estado para tomar parte em suas funções. A nacionalidade é um fato natural e a cidadania obedece a uma espécie de contrato. (...) A cidadania é portanto uma qualidade e um direito do cidadão que, como tal, possui a condição jurídica que ostentam as pessoas individuais ou coletivas com relação ao Estado a que pertencem, e que importa em submissão à autoridade e às leis vigentes e no livre exercício de certos direitos. Os meios de adquirir a cidadania variam de país a país e exigem requisitos diversos, de acordo com as legislações nacionais. (...) Hoje prossegue Juan Blasco Quintana — os autores discutem se o estudo do cidadão como tal é problema de direito público ou privado. Não há dúvida de que as instituições que têm caráter marcadamente público transcendem também a ordem particular; $\mathrm{e}$ ao contrário, qualquer questão que se realize no âmbito do direito privado acaba repercutindo na ordem geral e social; donde a dificuldade de se separar claramente as duas ordens. (...) A condição de cidadão - conclui Juan Blasco Quintana confere portanto ao indivíduo um status particular no sistema sócio-político".

A cidadania pode ser, assim, definida "como o estatuto oriundo do relacionamento existente entre uma pessoa natural e uma sociedade política, conhecida como o Estado, pelo qual a pessoa deve a este obediência e a sociedade lhe deve proteção". Esta a lição de Óscar Svarlien", que, em seguida, acrescenta que "Cidadania não deve ser confundida com domicílio, nem cidadão com habitante. $O$ indivíduo pode ser cidadão de um Estado sem ser habitante do mesmo, ou pode ser habitante sem ser cidadão", embora "Em ciência política e em sociologia, o termo cidadania é usado num sentido um pouco mais amplo".

Bem por isso, cuidando do estado atual da questão do direito dos cidadãos aos serviços públicos, por exemplo, Eduardo Garcia de Enterría e Tomás-Ramón Fernandez ${ }^{9}$ ensinam que ": Em uma primeira aproximação ao tema, cujo escasso tratamento na doutrina tradicional já em si mesmo suficientemente expressivo, é fácil constatar que todo ele aparece dominado por umas idéias prévias em extremo, simples. Como já vimos - continuam os festejados mestres espanhóis -, os textos constitucionais não são parcos em declarações relativas a prestações administrativas aos cidadãos, porém, tais declarações costumam carecer da precisão necessária para servir de base para um compromisso efetivo, possibilitando uma atitude de exigência do cidadão frente à Administração. No plano constitucional (...) não se definem, pois, nem obrigações propriamente tais dos entes públicos, nem direitos subjetivos do cidadão com relação a tais prestações, senão 'determinações de fins do Estado', próprias do Estado Social de Direito".

Lavrando uma "Teoria Geral dos Procedimentos de Exercício da Cidadania perante a Administração Pública”, José Alfredo de Oliveira Baracho ${ }^{10}$, ilustre Pro-

8 SVARLIEN, Oscar. Dicionário de Ciências Sociais, Coordenação Geral de Benedicto Silva, Editora da Fundação Getúlio Vargas, Rio de Janeiro, 1986, verbete "Cidadania”, p. 177.

9 GARCIA DE ENTERRÍA, Eduardo, e FERNÁNDEZ, Tomás-Ramón. Curso de Direito Administrativo, tradução de Arnaldo Setti e colaboração de Almudena Marín López e Elaine Alves Rodrigues, Editora Revista dos Tribunais, São Paulo, 1ª ed., 1991, p. 789 e seguintes. 
fessor de Minas Gerais, salientou que "A concepção moderna cidadania tem provocado diversos estudos que procuram examinar atualmente, o seu conteúdo. Este entendimento está ligado as diversas formas de participação política e também na própria Administração Pública. Constituições como a da Espanha e da Itália têm dedicado às instituições participativas. As teorias constitucionais clássicas, ao lado da teoria jusadministrativista, têm sido examinadas frente às mudanças sociais e institucionais dos tempos de hoje. O controle da atividade administrativa pelo cidadão, pode operar-se por diversos instrumentos públicos, que percorrem várias instâncias decisórias".

No Brasil, digo eu, por exemplo, há preocupação da defesa da cidadania quando, cuidando dos usuários de serviços públicos, o Código de Defesa do Consumidor, Lei Federal $\mathrm{n}^{\circ} 8.078$, de 11 de setembro de 1990, no seu artigo 22, caput e seu parágrafo único, respectivamente, estabeleceu que "Os órgãos públicos, por si ou suas empresas, concessionárias, permissionárias ou sob qualquer forma de empreendimento, são obrigados a fornecer serviços adequados, eficientes, seguros e, quanto aos essenciais, contínuos", certo que "Nos casos de descumprimento, total ou parcial, das obrigações referidas neste artigo, serão as pessoas jurídicas compelidas a cumpri-las e a reparar os danos causados, na forma prevista neste Código" ". Devemos, bem por isso, reconhecer um direito público subjetivo do cidadão aos serviços públicos, mesmo porque numa sociedade livre, há de estar garantida a convivência pacífica de todos os cidadãos, de tal modo que o exercício dos direitos de cada um não se transforme em abuso e não ofenda, não impeça e não perturbe o exercício dos direitos alheios.

A busca do bem comum, tenho presente, é missão primordial do Estado e de ninguém mais do que o Estado, porque, para tal mister ele se constituiu, a fim de, através de uma legislação adequada, instituições e serviços capazes de controlar, ajudar e regular as atividades privadas e individuais da vida nacional, possa cumprir a sua precípua missão de tudo fazer para convergir à realização dos ideais do bem comum, na plena realização da cidadania.

Daí poder ser afirmado que a segurança das pessoas e dos bens é o elemento básico das condições universais, fator absolutamente indispensável para o natural desenvolvimento da personalidade humana, como decorre do artigo 12 da bicentenária "Declaração dos Direitos do Homem e do Cidadão", como ainda da verdadeira "cláusula pétrea" contida no artigo $5^{\circ}$, caput, da Constituição Federal de 1988, que impõe a inviolabilidade do direito à vida, à liberdade, à segurança e à propriedade nas condições que explicita nos seus incisos, que cuidam "Dos Direitos e Deveres Individuais e Coletivos".

10 OLIVEIRA BARACHO, José Alfredo de. Teoria dos Procedimentos de Exercício da Cidadania perante a Administração Pública, "RBEP", Belo Horizonte, Separata do n 85, 1997, p. 7.

11 Sobre SERVIÇOS PÚBLICOS NAS RELAÇÕES DE CONSUMO, conferir nossa monografia publicada na Revista "A Força Policial", órgão de informação da Polícia Militar do Estado de São Paulo, Imprensa Oficial do Estado de São Paulo, São Paulo, Ano 1998, abril/maio/junho, n 18, p. $05-14$ 
"A democracia - afirma José Alfredo de Oliveira Baracho ${ }^{12}$ - implica a participação dos cidadãos, não apenas nos negócios públicos, mas na realização de todos os direitos e garantias consagrados na Constituição e nos diversos segmentos do ordenamento jurídico global. O direito constitucional moderno inclui a garantia dos direitos fundamentais, que se efetiva por meio de ações constitucionais típicas, que se concretizam, também, por intermédio das ações, processos e procedimentos, que tornam possível a participação da cidadania, em seus diversos aspectos e consequiências. A completa proteção da cidadania depende de práticas institucionais, constitucionais, jurídicas, processuais e políticas, que protegem o ser humano nas mais variadas situações e posições."

Observo, contudo, com Vera Regina Pereira de Andrade ${ }^{13}$, "Na perspectiva em que se insere, o saber jurídico tem esgotada sua operacionalidade e possibilidades de eficácia no encaminhamento da problemática da cidadania e de suas formas emergentes de positivação; ou seja, torna-se impotente para operar uma efetiva função social, capaz de contribuir no repensar da cidadania e de suas passagens potenciais do instituinte ou do instituído. Dessa forma, no contexto estrutural de crise, por que passa também a cultura jurídica dominante, o discurso jurídico da cidadania é um discurso em crise: 'A crise consiste precisamente no ato de que o velho está morrendo e o novo não pode nascer; neste interregno, surge uma grande variedade de sintomas móbidos'. (...) Parece então fundamental reivindicar simultaneamente uma nova diretriz científica e política para o saber jurídico através da constituição de uma nova teoria jurídica que, suplantando o nível puramente teórico, articule teoria e práxis, (conhecimento e realidade) mediante uma postura dialética sobre o Direito a partir de seu próprio interior: as relações de força na sociedade. No mesmo movimento, parece ser fundamental promover-se o diálogo do saber jurídico com os demais saberes, de forma a superar a clausura monológica a que $o$ condenam o positivismo e o liberalismo. Uma teoria crítica das relações nocivas, que promova a articulação das complexas relações teoria/praxis, parece ser uma possibilidade de superação das construções dogmáticas, mantenedoras do status que é um caminho para a construção de um saber jurídico comprometido com a transformação democrática da sociedade e o encaminhamento de efetivas soluções para os problemas nacionais dentre os quais a cidadania ocupa destacado lugar".

Falar, portanto, em cidadania, como sustenta Milena Petters Melo ${ }^{14}$, "é reafirmar o direito pela plena realização do indivíduo, do cidadão, dos entes coletivos e de sua emancipação nos espaços definidos no interior da sociedade. Os conceitos de cidadania, democracia e direitos humanos estão intimamente ligados, um remete ao outro, seus conteúdos interpenetram-se: a cidadania não é constatável sem a realização dos Direitos Humanos, da mesma forma que os Direitos Humanos, não se concretizam

12 OLIVEIRA BARACHO, José Alfredo de. Teoria Geral da Cidadania, Editora Saraiva, São Paulo, p. 63.

13 PEREIRA DE ANDRADE, Vera Regina. CIDADANIA: Do Direito aos Direitos Humanos, Editora Acadêmica, São Paulo, 1993, p. 136.

14 MELO, Milena Petters, et alii. Obra e ed. cits., p. 79 e 81 
sem o exercício da democracia", razão de poder-se "afirmar, portanto, que a realização plena dos direitos de cidadania envolve o exercício efetivo e amplo dos direitos humanos, nacional e internacionalmente assegurados. No âmbito do direito constitucional positivo. a cidadania, em sua forma integral, pressupõe o exercício de todos os direitos fundamentais e garantias que caracterizam o Estado Democrático de Direito", observado que a expressão "direitos fundamentais", no seu estudo em exame, "é utilizada para designar os direitos humanos positivados, institucionalizados, que encontraram reconhecimento no direito positivo dos Estados".

\section{Direitos Humanos fundamentais}

Locução desgastada pelo seu mau uso ${ }^{15}$, com fins político-ideológicos, normalmente associados à proteção de marginais em detrimento à proteção das suas vítimas e dos Encarregados da Aplicação da Lei. os denominados "Direitos Humanos", ao contrário, têm significado que transcende a tudo isto, sendo oportuno, desde logo, trazer à colação a posição de Alexandre de Moraes $^{16}$ no sentido de que "O conjunto institucionalizado de direitos e garantias do ser humano que tem por finalidade básica o respeito à sua dignidade, por meio de sua proteção contra o arbítrio do poder estatal e o estabelecimento de condições mínimas de vida e desenvolvimento da personalidade humana pode ser definido como direitos humanos fundamentais".

Christophe Swinarski, em sua obra "Direito Internacional Humanitário" 17 . lembra que "Os Direitos Humanos, como se sabe, como ramo autônomo do Direito Internacional Público com seus próprios instrumentos, seus próprios órgãos e seus próprios procedimentos de aplicação, nasceram na normativa internacional a partir da Carta das Nações Unidas de 1945. O seu primeiro catálogo metódico é enunciado na Declaração Universal dos Direitos do Homem em 1948”, havendo, porém, um diferencial entre o que se denomina de "Direitos Humanos" e o que se denomina de "Direito Internacional Humanitário", porque, "O Direito Internacional Humanitário é um direito de exceção, de urgência, que intervém em caso de ruptura da ordem jurídica internacional (e quando interno no caso do conflito não-internacional). enquanto os Direitos Humanos — embora alguns deles sejam inderrogáveis em qualquer circunstância - aplicam-se. principalmente. em tempos de paz". O citado autor, aliás. já tinha anotado que " $\mathrm{Na}$ primeira época da coexistência do "novo" direito dos Direitos Humanos com o 'velho' Direito Humanitário encontra-se algu-

15 Os marginais. por exemplo. dizem que os “Direitos Humanos" são os Direitos “dos Manos", ou seja. da marginalidade. O povo ordeiro tem dado também tal conotação. quando critica os defensores dos "Direitos Humanos". dizendo que eles só se preocupam com os bandidos e não com as suas vítimas.

16 MORAES, Alexandre de. Direitos Humanos Fundamentais e Democracia. Editorial ATLAS

- Direito. Editora ATLAS, São Paulo, p. 5.

17 SWINARSKI. Christofhe. Direito Internacional Humanitário, Núcleo de Estudos da Violência — Universidade de São Paulo/Editora Revista dos Tribunais. São Paulo, 1990, p. 87 e seguintes. 
mas controvérsias sobre a localização respectiva de ambos os ramos no direito internacional, assim como sobre suas inter-relações. Os Direitos Humanos apareciam como o sistema representativo, por excelência, das novas idéias da comunidade internacional e como um conceito jurídico que deveria fundamentar a possibilidade de conseguir os outros objetivos da Carta, entendida como no sistema universal da segurança coletiva e da paz".

Mas, há também, um "Direito Internacional dos Direitos Humanos”, que, conforme o Comitê Internacional da Cruz Vermelha Internacional ${ }^{18}$, " pode ser dividido, para os objetivos do presente Manual, em instrumentos $\mathrm{com}$ força legal (por exemplo, direito dos tratados) e instrumentos sem força legal (diretrizes, princípios, códigos de conduta etc.)". E, em "Pontos de Destaque do Capítulo", registrou-se que "O direito internacional de direitos humanos e o direito internacional humanitário têm importância direta para a prática de aplicação da lei”, sendo que "As práticas de aplicação da lei devem ser vistas como práticas do Estado, estando, dessa forma, de total acordo com as obrigações de um Estado perante o direito internacional", ressaltando-se que "A promoção e a proteção das liberdades e direitos humanos são da responsabilidade tanto coletiva quanto individual no que diz respeito à aplicação da lei".

Lembre-se, a propósito, que o Comitê Internacional da Cruz Vermelha (CICV) organização imparcial, neutra e independente, possui a missão exclusivamente humanitária de proteger a vida e a dignidade das vítimas da guerra e da violência interna, assim como prestar-lhe assistência, ou, em outras palavras, não está engajado em facções político-ideológicas que deturparam o significado da locução "Direitos Humanos".

Há e deve haver, ao certo, uma relatividade dos Direitos Humanos, observando Alexandre de Moraes ${ }^{19}$, com apoio na própria "Declaração dos Direitos Humanos das Nações Unidas", artigo 28, que "Os direitos humanos fundamentais não podem ser utilizados como um Verdadeiro escudo protetivo da prática de atividades ilícitas, nem tampouco como argumento para afastamento ou diminuição da responsabilidade civil ou penal por atos criminosos, sob pena de total consagração ao desrespeito a um verdadeiro Estado de Direito. Os direitos e garantias fundamentais consagrados pela Constituição Federal, portanto, não são ilimitados uma vez que encontram seus limites aos demais direitos igualmente consagrados pela Carta Magna (Princípio da relatividade ou convivência das liberdades públicas). Dessa forma, quando houver conflito entre dois ou mais direitos ou garantias fundamentais, o intérprete deve utilizar-se do princípio da concordância ou da harmonização, de forma a coordenar e combinar os bens jurídicos em conflito, evitando o sacrifício total de uns em relação aos outros, realizando uma redução do âmbito de alcance de cada qual (contradição

18 COMITE INTERNACIONAL DA CRUZ VERMELHA, Para Servir e Proteger - Direitos Humanos e Direito Internacional Humanitário para Forças Policiais e de Segurança, Capítulo 4 - Aplicação da Lei nos Estados Democráticos, Manual (sem indicação de Editora e ano), p. 6

19 MORAES, Alexandre de. Direitos Humanos Fundamentais. Coleção TEMAS JURÍDICOS. v. 3, Editora ATLAS, São Paulo. 1997. p. 46 
dos princípios), sempre em busca do verdadeiro significado da norma e da harmonia do texto constitucional com suas finalidades precípuas".

\section{1 - Proteção às vítimas. Considerações}

Reconheço, porém, que, conforme o atesta o Comitê Internacional da Cruz Vermelha ${ }^{20}$, "Considerando os inúmeros instrumentos que estipulam os direitos e a situação dos suspeitos e acusados, o fato que haja somente um instrumento protegendo as vítimas da criminalidade e do abuso de poder nos oferece uma visão desconcertante das prioridades em questão. Não parece justo que seus direitos e situação sejam protegidos tão precariamente quando comparados aos níveis de proteção oferecidos; aos infratores. A proteção às vítimas do crime é muito limitada, quando comparada ao número de instrumentos destinados à proteção dos direitos dos suspeitos e pessoas acusadas nas áreas de captura, detenção, prevenção e detecção do crime. (...) Somente uns poucos dispositivos de tratados criam obrigações aos Estados Partes com respeito aos tratamento das vítimas do crime e do abuso do poder", sustentando-se, no entanto, que os Encarregados da Aplicação da Lei (leia-se, os agentes policiais) devem ser "convencidos de que o bem-estar das vítimas deveria ser da mais alta prioridade. Não se pode desfazer o crime cometido, porém, o auxílio e a assistência adequados fazem com que as consequiências negativas do crime para com as vítimas sejam definitivamente limitadas".

\section{O Poder Judiciário como instrumento de defesa da cidadania e dos Direitos Humanos fundamentais}

Cuidando do "Direito, Cidadania e Justiça", Oscar Vilhena Vieiraa ${ }^{21}$ sustenta que "Para que os indivíduos possam efetivamente fruir esses direitos, é necessário que o Estado seja estruturado de uma forma específica voltada a limitar o seu poder. A regra fundamental desse modelo de Estado é a separação de poderes, sendo garantido aos indivíduos a possibilidade de recorrerem a um poder judiciário todas as vezes que se virem ameaçados em seus direitos. Toda ordem estatal, todas as suas autoridades e decisões, inclusive as legais, devem estar submetidas a esses direitos. Nesse sentido, a idéia de Estado de Direito se torna um elemento essencial à consolidação, aprofundamento e sobrevivência do regime democrático. A democracia exige essa normalidade, pois fora dela não há como se falar em garantia de direitos. Pressupõe um ambiente estruturado com base numa racionalidade legal, dotado de instituições jurídicas que respondam a uma ética própria do espaço público. Toda vez que esse sistema for colocado em xeque a democracia estará em risco".

20 COMITÊ INTERNACIONAL DA CRUZ VERMELHA, Obra cit., Capítulo 13, p. 2 e 5.

21 VIEIRA, Oscar Vilhena. A violação dos Direitos Humanos como limite à consolidação do Estado de Direito no Brasil, Ensaio sobre “Direito, Cidadania e Justiça, coordenação de Beatriz Di Giorgi et alii, Editora Revista dos Tribunais, São Paulo, 1995, p. 191. 
$\mathrm{Na}$ estrutura do Estado brasileiro, como é cediço, cabe, em especial, ao Poder Judiciário a garantia da cidadania e dos Direitos Humanos, lembrando Alexandre de Moraes $^{22}$ que "A Constituição Federal reconhece em situações excepcionais e gravíssimas a possibilidade de restrição ou supressão temporária de direitos e garantias fundamentais, prevendo-se sempre, porém, responsabilização do agente público em caso de utilização dessas medidas de forma injustificada e arbitrária".

O agente público, em especial aquele a que se incumbiu a aplicação da lei (entenda-se os agentes de polícia), assim, há de ser responsabilizado perante um Poder autônomo e independente, evitando-se, deste modo, ser ele, também, julgado precipitadamente, no fragor dos acontecimentos, num verdadeiro linchamento, que violará, ao certo, também, os seus Direitos Humanos, cidadãos que também é.

Todos sabemos e Alexandre de Moraes ${ }^{23}$, citando diversos autores, afirma que "O Poder Judiciário é um dos três poderes clássicos previstos pela doutrina e consagrado como um poder autônomo e independente de importância crescente no Estado de Direito, pois, como afirma Sanches Viamonte (Manual del derecho politico. Buenos Aires: Bibliográfico Argentino, (s.d.), p. 212), sua função não consiste somente em administrar a Justiça, pura e simplesmente, sendo mais, pois seu mister é ser o verdadeiro guardião da Constituição, com a finalidade de preservar os direitos humanos fundamentais e, mais especificadamente, os princípios da legalidade e igualdade, sem os quais os demais tornariam-se (sic) vazios. Não se consegue conceituar um verdadeiro Estado de direito democrático sem a existência de um Poder Judiciário autônomo e independente para que exerça sua função de guardião das leis, pois, como afirmou Zaffaroni, 'a chave do Poder Judiciário se acha no conceito de independência' (Poder Judiciário. Tradução: Juarez Tavares. São Paulo: Revista dos Tribunais, 1995, p. 87). Bandrés - também citado por Alexandre de Moraes - afirma que a independência judicial constitui um direito fundamental dos cidadãos, inclusive o direito à tutela judicial e o direito ao processo e julgamento por um Tribunal independente e imparcial (Poder Judicial y Constitución. Barcelona; Bosch-Casa Editorial, 1987. p. 12). (...) Dessa forma - ponderou Alexandre de Moraes - competirá ao Poder Judiciário garantir e efetivar o pleno respeito aos direitos humanos fundamentais, sem que possa a lei excluir de sua apreciação qualquer lesão ou ameaça de direito (CF, art. $\left.5^{\circ}, \mathrm{XXXV}\right)$ ".

\section{Conclusão}

Podemos, a partir dos fundamentos doutrinários retro elencados, concluir que

5.1 - A dignidade humana decorre do preceito bíblico de que o homem foi feito à imagem e semelhança de Deus. O homem, porém, tem violado o princípio divino de sua dignidade. Para ele o valor supremo não é mais Deus e sim o próprio homem.

22 MORAES, Alexandre de. Direitos Humanos Fundamentais, ed. cit. p. 47.

23 MORAES, Alexandre de. Direitos Humanos Fundamentais, ed. cit., p. 51-52 
5.1.1. - Mas, de qualquer modo, a sociedade fez-se para o homem e não o homem para a sociedade, o que, no entanto, não quer dizer que a sociedade se encontra subordinada a atividade egoística do homem, pois este há de colaborar com os demais homens da sociedade em que vive.

5.2 - O homem é o cidadão que vive em uma determinada sociedade. $O$ fato de ser cidadão propicia a cidadania. Esta é a condição jurídica que podem ostentar as pessoas físicas e morais, e que por expressar o vínculo entre o estado e seus membros implica de um lado, submissão à autoridade, e de outro, o exercício de direito. O cidadão é membro ativo de uma sociedade política independente.

5.2.1 - Pode-se afirmar que a realização plena dos direitos de cidadania envolve o exercício efetivo e amplo dos direitos humanos, nacional e internacionalmente assegurados.

5.3 - Tais Direitos Humanos, nacional e internacional assegurados, são Direitos Humanos Fundamentais, com o tal considerados os positivados, isto é, institucionalizados por um Estado.

5.3.1 - É válida a posição de Alexandre de Moraes no sentido de que "o conjunto institucionalizado de direitos e garantias do ser humano que tem por finalidade básica o respeito à sua dignidade, por meio de sua proteção contra o arbítrio do poder estatal e o estabelecimento de condições mínimas de vida e desenvolvimento da personalidade humana pode ser definido como direitos humanos fundamentais".

5.3.2 - Os "Direitos Humanos", atualmente, não se confundem com o "Direito Internacional Humanitário". Há, realmente, um diferencial entre o que se denomina de "Direitos Humanos" e o que se denomina de "Direito Internacional Humanitário", porque, o "Direito Internacional Humanitário" intervém em caso de violação da ordem jurídica internacional ou na hipótese de conflito interno não-internacional; os "Direitos Humanos", por sua vez, aplicam-se, principalmente, em tempos de paz.

6 - O Poder Judiciário é um dos principais, senão o principal, instrumentos de defesa da cidadania e dos Direitos Humanos Fundamentais, contra os desmandos do Estado.

6.1 - Daí por que, em tempos que procuram desacreditá-lo, minimizando as suas prerrogativas e de seus juízes, urge que as forças vivas da cidadania, assim também ameaçada, se unam em defesa do Poder Judiciário e, portanto, dos Direitos Humanos Fundamentais dos cidadãos. 